\title{
Association Study of TRPC4 as a Candidate Gene for Generalized Epilepsy with Photosensitivity
}

\author{
Sarah von Spiczak • Hiltrud Muhle - Ingo Helbig • Carolien G. F. de Kovel • \\ Jochen Hampe - Verena Gaus - Bobby P. C. Koeleman - Dick Lindhout • \\ Stefan Schreiber · Thomas Sander · Ulrich Stephani
}

Received: 19 April 2010/Accepted: 11 June 2010/Published online: 24 June 2010

(C) Springer Science+Business Media, LLC 2010

\begin{abstract}
Photoparoxysmal response (PPR) is characterized by abnormal visual sensitivity of the brain to photic stimulation. Frequently associated with idiopathic generalized epilepsies (IGEs), it might be an endophenotype for cortical excitability. Transient receptor potential cation (TRPC) channels are involved in the generation of epileptiform discharges, and TRPC4 constitutes the main TRPC channel in the central nervous system. The present study investigated an association of PPR with sequence variations of the TRPC4 gene. Thirty-five single nucleotide
\end{abstract}

S. von Spiczak ( $₫) \cdot$ H. Muhle $\cdot$ I. Helbig · U. Stephani Department of Neuropediatrics, University Hospital SchleswigHolstein, Campus Kiel, Arnold-Heller-Str.3, Building 9, 24105 Kiel, Germany

e-mail: s.vonspiczak@pedneuro.uni-kiel.de

T. Sander

Cologne Center for Genomics, University of Cologne,

Zülpicher Straße 47, 50674 Cologne, Germany

C. G. F. de Kovel - B. P. C. Koeleman - D. Lindhout

DBG-Department of Medical Genetics, University Medical

Center, Universiteitsweg 100, 3584 CG Utrecht,

The Netherlands

\section{J. Hampe $\cdot$ S. Schreiber}

Institute for Clinical Molecular Biology, Christian-Albrechts

University Kiel, Schittenhelmstr. 12, 24105 Kiel, Germany

V. Gaus

Department of Neurology, Charité University Medicine, Campus Virchow Clinic, Humboldt University of Berlin, Augustenburger Platz 1, 13353 Berlin, Germany

D. Lindhout

SEIN Epilepsy Institute in the Netherlands,

Achterweg 5, 2103 SW Heemstede, The Netherlands polymorphisms (SNP) within TRPC4 were genotyped in 273 PPR probands and 599 population controls. Association analyses were performed for the broad PPR endophenotype (PPR types I-IV; $n=273$ ), a narrow model of affectedness (PPR types III and IV; $n=214$ ) and PPR associated with IGE (PPR/IGE; $n=106)$ for each SNP and for corresponding haplotypes. Association was found between the intron 5 SNP rs10507456 and PPR/IGE both for single markers $(P=0.005)$ and haplotype level $(P=0.01)$. Three additional SNPs (rs1535775, rs10161932 and rs7338118) within the same haplotype block were associated with PPR/IGE at $P<0.05$ (uncorrected) as well as two more markers (rs10507457, rs7329459) located in intron 3. Again, the corresponding haplotype also showed association with PPR/IGE. Results were not significant following correction for multiple comparisons by permutation analysis for single markers and Bonferroni-Holm for haplotypes. No association was found between variants in TRPC4 and other phenotypes. Our results showed a trend toward association of TRPC4 variants and PPR/IGE. Further studies including larger samples of photosensitive probands are required to clarify the relevance of TRPC4 for PPR and IGE.

Keywords Photosensitivity - IGE - Endophenotype · Candidate gene $\cdot$ TRPC4

\section{Introduction}

Photosensitivity (photoparoxysmal response, PPR) is characterized by abnormal visual sensitivity of the brain to photic stimulation and can be elicited by standardized intermittent photic stimulation applied during the EEG recording (Fisher et al. 2005). This EEG trait is thought to characterize increased generalized cortical excitability 
(Siniatchkin et al. 2007). It occurs in about $3 \%$ of the general population (Fisher et al. 2005) but is present at higher frequencies in patients with idiopathic generalized epilepsies (Covanis 2005). Depending on stimulation procedures and age of examination, it may be provoked in up to $90 \%$ of patients with juvenile myoclonic epilepsy (JME) (Appleton et al. 2000). As PPR is thought to be highly heritable (Doose et al. 1969; Stephani et al. 2004), we use this electroencephalographic feature as an endophenotype for idiopathic generalized epilepsies, which show genetic heterogeneity and complex inheritance. We looked for potential candidate genes for photosensitivity based on their biological functions and a possible role in epileptogenesis. The candidate gene chosen for association analysis was TRPC4, a transient receptor potential cation channel (member 4 of subfamily C, OMIM $* 603651$, localized on chromosome 13q13.1-q13.2 (McKay et al. 2000)). The protein encoded by TRPC4 forms a calcium-permeable, non-selective cation channel activated by $\mathrm{Ca}^{2+}$ storedepletion as well as second-messenger-mediated pathways regulating vascular tone, endothelial permeability, and neurotransmitter (i.e. GABA) release from thalamic interneurons (Munsch et al. 2003; Freichel et al. 2005). Therefore, this candidate gene fits well into the model of channelopathies as a major underlying pathogenic mechanism in epilepsy (Reid et al. 2009).

\section{Methods}

\section{Patients}

Two hundred and seventy-three probands exhibiting PPR (inclusion criteria: PPR type I-IV according to (Waltz et al. 1992) elicited by standardized stimulation procedures (ILAE 1989)) and 599 population controls (for details see Table 1) were recruited at the Clinic for Neuropediatrics at the University Hospital Schleswig-Holstein (Kiel, Germany) and the Department of Neurology of the Charite University Medicine (Berlin, Germany). All of them gave written informed consent for participation in the study. The study was conducted according to the Declaration of Helsinki, and the study protocol was approved by the local ethics committees at the study sites. The epilepsy diagnoses of photosensitive probands were performed according to the ILAE classification scheme (Engel 2001) and are given in Table 1. Non-epileptic diagnoses included $\mathrm{AD}(\mathrm{H}) \mathrm{D}$, headache, migraine, syncope and tic disorder. All subjects were Caucasians of German origin (self-reporting), and controls are without a history of major neurological and psychiatric disorders (screened by questionnaire or standardized interviews). In controls, no EEGs were performed.
Table 1 Diagnoses of PPR-positive probands according to the ILAE classification scheme

\begin{tabular}{c|c|c|c|c|c|c|c|c|c|c}
\hline & Controls & \multicolumn{2}{|c|}{ PPR positive with IGE } & \multicolumn{3}{|c}{ PPR positive without IGE } \\
\hline \hline Analysed & 599 & \multicolumn{2}{|c|}{106} & \multicolumn{4}{|c}{167} \\
Subgroups & $\begin{array}{c}\text { IGE } \\
\text { n.c. }\end{array}$ & CAE & JAE & JME & $\begin{array}{c}\text { PPR } \\
\text { only }\end{array}$ & FS & PSE & focal & n. c. \\
\hline \hline Analysed & 17 & 37 & 11 & 41 & 83 & 11 & 9 & 28 & 36 \\
\hline
\end{tabular}

Abbreviations: $I G E$ n.c. idiopathic generalized epilepsy not classified (cases not classified as CAE, JAE or JME, i.e. patients with generalized tonic-clonic seizures, mostly on awakening, and typical generalized spike-wave paroxysms on EEG recordings); $C A E$ childhood absence epilepsy, $J A E$ juvenile absence epilepsy, $J M E$ juvenile myoclonic epilepsy, PPR only no epilepsy or seizures, $F S$ febrile seizures, PSE seizures induced by photic stimulation only, focal focal epilepsies, n.c. not classified

\section{Genotyping}

DNA from individual blood samples was extracted using commercially available kits (FlexiGen DNA Kit ${ }^{\circledR}$ by QUIAGEN GmbH, Germany). Because of the size of the TRPC4 gene (chromosomal position: 37,108,778-37,342,562; size $234 \mathrm{~kb}$; 11 exons; ENSEMBL transcript ID ENST00 000379705), exon boundaries $\pm 5 \mathrm{~kb}$ were used for defining a total of 43 tagging single nucleotide polymorphisms (SNP) covering the whole gene in Haploview ${ }^{\circledR} 4.1$ (http://www .broad.mit.edu/mpg/haploview/; defaults: minor allele frequency 0.05 , Hardy-Weinberg $P$-value cut-off 0.01 , pairwise tagging only, r2 threshold 0.8). SNPlexTM System Ligation Probes (AppliedBiosystems, Foster City, CA, USA) were used for SNP genotyping (Tobler et al. 2005).

\section{Data analysis}

The following subgroups were analyzed separately: "PPR types I-IV" (all 273 probands), "PPR types III and IV $(n=214)$ ", and "PPR associated with IGE" $(n=106)$. Data were analyzed using Haploview ${ }^{\circledR} 4.1$ (Barrett et al. 2005). Quality control revealed at least $70 \%$ of SNPs genotyped in all subjects. SNPs with call rates less than 95\% were excluded from further analysis. In addition to association testing (Chi-square test) for allele frequencies of single markers, a haplotype analysis was performed as implemented in Haploview ${ }^{\circledR} 4.1$ (Barrett et al. 2005) for SNPs located within LD blocks (default parameters: association test, case/control, ignore pairwise comparisons of markers $<500 \mathrm{~kb}$ apart; set parameter: exclude individuals with $>30 \%$ of genotypes missing, minor allele frequency $>1 \%$, Hardy-Weinberg $P$-value cut-off 0.01 ). In order to correct for multiple comparisons, permutation testing was done for single markers (1,000 permutations) as well as haplotypes by Bonferroni-Holm correction. Power calculation (Skol et al. 2006) for the whole group revealed a likelihood of $80 \%$ to detect a sequence variant with a 
presumed disease allele frequency of $3 \%$ and a relative risk of 1.87 and a probability of $95 \%$ to find a polymorphism with a presumed disease allele frequency of $5 \%$ and, again, a relative risk of 1.87 .

\section{Results}

In total, association analysis was carried out for 35 SNPs in 167 PPR-positive subjects without IGE, 106 PPR-positive IGE patients, 214 probands with PPR III and IV (thereof 98 PPR + IGE) and 599 control subjects. None of the genotype distributions in controls deviated significantly from those expected by Hardy-Weinberg equilibrium (HWE, $P>0.09$ ). Six single markers (rs10507456, rs1535775, rs10161932, rs7338118, rs10507457 and rs7329459) showed nominal $P<0.05$ with the PPR/IGE phenotype (Table 2). These polymorphisms are located in two different haplotype blocks (block 2 comprising SNPs 3-15 and block 3 comprising SNPs 17-22, respectively), which, as well, showed nominal $P$-values $<0.05$ for PPR/IGE. Haplotype frequencies associated with PPR/IGE are demonstrated in Table 3, and haplotype blocks are illustrated in Fig. 1. Following permutation analysis for single markers empirical $P$-values revealed only a trend toward significance with $P=0.1$ for rs10507456. For haplotypes, correction for multiple comparisons was done by Bonferroni-Holm; however, no significant results were seen. There were no associations with any other phenotype investigated (PPR, PPR grade III and IV).

\section{Discussion}

Endophenotypes are a useful tool to investigate the genetic background of common complex diseases-using the assumption that the genetic basis of the endophenotype is less complex than the disease itself, i.e. comprising a smaller number of pathogenic genetic alterations. The concept has been widely accepted, especially for psychiatric disorders (Gottesman and Gould 2003; Cannon and Keller 2006) but also for neurological syndromes (Stefansson et al. 2007) and other conditions (Lalouel et al. 1985; Darbar et al. 2008). Endophenotypes suitable for genetic studies are objectifiable, i.e. measurable features of a disease. Therefore, they should be of particular benefit for studies investigating disorders that are diagnosed based on clinical observation and description such as psychiatric diseases and epilepsy. Gottesman and Gould (2003) state that endophenotypes should be associated with a specific disease, be heritable, co-segregate within families, show higher incidence in patients with a specific disease as well as in their (non-affected) families compared to the general population. PPR fulfills all the previously listed requirements and, therefore, may be used as an endophenotype for IGE (Helbig et al. 2008). PPR is often found in patients with IGE. Using the PPR endophenotype provides the researcher with the advantage of a very distinct and welldefined EEG trait easy to diagnose for the trained EEG interpreter. Former studies on the genetic background of photosensitivity failed to demonstrate reproducible major effects of the genes investigated including BRD2 and NEDD4-2 (Lorenz et al. 2006; Dibbens et al. 2007).

A total of six single markers localized in two haplotype blocks showed a trend toward association with the phenotype of PPR and idiopathic generalized epilepsy. Furthermore, the two haplotype blocks (blocks 2 and 3) were also associated with PPR + IGE. No associations were found for the subgroups of "PPR" and the narrower model of affectedness including only probands with PPR grade III and IV. These findings suggest that variants in TRPC4 might predispose to a combined phenotype of IGE and PPR but not to a broad PPR phenotype indicating genetic heterogeneity within the PPR endophenotype with different genetic backgrounds for "PPR in the context of IGE" and "PPR without IGE".

The group of PPR-positive probands without IGE which comprised probands without epilepsy as well as patients with simple febrile seizures or other types of epilepsy might have been too heterogeneous with respect to phenotypes as well as the genetic background of the different clinical conditions to detect any significant associations with polymorphisms of TRPC4. Breaking down phenotypes more precisely would be a possibility to overcome this problem; however, recruitment of sufficient numbers of probands becomes more difficult with more specific inclusion criteria. Furthermore, controls had no EEG prior to inclusion in the study, and undetected photosensitivity has to be assumed in a proportion of them according to the (age-related) incidence of photosensitivity of approximately 3\% in the normal population. Performance of EEGs in large control cohorts is not feasible and recruitment of pediatric control subjects ethically not justifiable. As association studies require large sample sizes of probands and controls to detect common variants with low effect sizes, the practicability of such studies is limited (Mullen et al. 2009). Here, by only reaching modest association in a top candidate gene, we reach the limitations of the (PPR) endophenotype approach for genetic association studies.

Our results do not bear up correction for multiple comparisons, although there was at least a trend toward significance for rs 10507456 in the PPR/IGE group. Again, this reflects the problem of using distinct endophenotypes with smaller sample sizes which will reduce the power to detect or confirm relative weak associations (Newton-Cheh 
Table 2 Polymorphisms and $P$-values (for allele frequencies) for PPR + IGE

\begin{tabular}{|c|c|c|c|c|c|c|c|c|}
\hline \# SNP & dbSNP ID & Position & Location & $\begin{array}{l}\text { Major/minor } \\
\text { allele }\end{array}$ & $\begin{array}{l}\text { MAF } \\
\text { cases }\end{array}$ & $\begin{array}{l}\text { MAF } \\
\text { controls }\end{array}$ & $P$ Value & $\begin{array}{l}P \text { Value, } \\
\text { corrected }\end{array}$ \\
\hline 13 & rs 10507456 & 37140190 & Intron 5 & $\mathrm{G}>\mathrm{A}$ & 0.18 & 0.11 & 0.005 & 0.102 \\
\hline 5 & rs1535775 & 37118959 & Intron 8 & $\mathrm{G}>\mathrm{A}$ & 0.27 & 0.19 & 0.014 & 0.267 \\
\hline 3 & rs10161932 & 37108931 & $3^{\prime}$ & $\mathrm{C}>\mathrm{T}$ & 0.27 & 0.20 & 0.018 & 0.322 \\
\hline 10 & rs7338118 & 37126456 & Intron 7 & $\mathrm{~A}>\mathrm{C}$ & 0.26 & 0.19 & 0.020 & 0.341 \\
\hline 22 & rs 10507457 & 37167676 & Intron 3 & $\mathrm{C}>\mathrm{T}$ & 0.10 & 0.06 & 0.021 & 0.367 \\
\hline 18 & rs7329459 & 37140639 & Intron 5 & $\mathrm{G}>\mathrm{A}$ & 0.27 & 0.21 & 0.047 & 0.596 \\
\hline 11 & rs2985167 & 37128542 & Intron 6 & $\mathrm{G}>\mathrm{A}$ & 0.43 & 0.36 & 0.060 & 0.676 \\
\hline 26 & rs2025404 & 37216204 & Intron 3 & $\mathrm{~T}>\mathrm{C}$ & 0.33 & 0.37 & 0.221 & 0.985 \\
\hline 15 & rs7321872 & 37144607 & Intron 5 & $\mathrm{~A}>\mathrm{G}$ & 0.25 & 0.28 & 0.257 & 0.992 \\
\hline 8 & rs9532093 & 37124861 & Intron 7 & $\mathrm{C}>\mathrm{G}$ & 0.22 & 0.26 & 0.258 & 0.992 \\
\hline 24 & rs7317546 & 37168808 & Intron 3 & $\mathrm{~A}>\mathrm{T}$ & 0.35 & 0.39 & 0.334 & 0.999 \\
\hline 2 & rs9547988 & 37108231 & $3^{\prime}$ & $\mathrm{T}>\mathrm{G}$ & 0.31 & 0.35 & 0.343 & 0.999 \\
\hline 23 & rs9315508 & 37167944 & Intron 3 & $\mathrm{~A}>\mathrm{T}$ & 0.46 & 0.49 & 0.350 & 1.000 \\
\hline 17 & rs1924304 & 37146655 & Intron 4 & $\mathrm{~A}>\mathrm{G}$ & 0.52 & 0.49 & 0.381 & 1.000 \\
\hline 34 & rs1924379 & 37341712 & Intron 1 & $\mathrm{C}>\mathrm{A}$ & 0.31 & 0.34 & 0.382 & 1.000 \\
\hline 30 & rs12583681 & 37255494 & Exon 2 & $\mathrm{G}>\mathrm{A}$ & 0.13 & 0.15 & 0.382 & 1.000 \\
\hline 32 & rs1924377 & 37260106 & Intron 1 & $\mathrm{G}>\mathrm{C}$ & 0.47 & 0.44 & 0.410 & 1.000 \\
\hline 1 & rs2985164 & 37105807 & $3^{\prime}$ & $\mathrm{G}>\mathrm{A}$ & 0.32 & 0.35 & 0.421 & 1.000 \\
\hline 27 & rs12869943 & 37254247 & Intron 2 & $\mathrm{~A}>\mathrm{G}$ & 0.24 & 0.26 & 0.440 & 1.000 \\
\hline 6 & rs12856733 & 37122149 & Intron 8 & $\mathrm{C}>\mathrm{T}$ & 0.34 & 0.37 & 0.486 & 1.000 \\
\hline 35 & rs3812840 & 37342482 & Exon 1 & $\mathrm{~A}>\mathrm{G}$ & 0.27 & 0.29 & 0.541 & 1.000 \\
\hline 12 & rs2957214 & 37135384 & Intron 6 & $\mathrm{G}>\mathrm{A}$ & 0.34 & 0.36 & 0.561 & 1.000 \\
\hline 7 & rs9566245 & 37123131 & Intron 8 & $\mathrm{~A}>\mathrm{G}$ & 0.34 & 0.36 & 0.565 & 1.000 \\
\hline 33 & rs9603267 & 37337915 & Intron 1 & $\mathrm{G}>\mathrm{C}$ & 0.17 & 0.18 & 0.645 & 1.000 \\
\hline 20 & rs9548017 & 37159906 & Intron 4 & $\mathrm{C}>\mathrm{T}$ & 0.15 & 0.16 & 0.677 & 1.000 \\
\hline 19 & rs4943532 & 37151427 & Intron 4 & $\mathrm{C}>\mathrm{T}$ & 0.33 & 0.34 & 0.648 & 1.000 \\
\hline 28 & rs 12875527 & 37255384 & Exon 2 & $\mathrm{G}>\mathrm{A}$ & 0.10 & 0.10 & 0.813 & 1.000 \\
\hline 29 & rs3904512 & 37255471 & Exon 2 & $\mathrm{G}>\mathrm{A}$ & 0.40 & 0.41 & 0.824 & 1.000 \\
\hline 14 & rs9548010 & 37142897 & Intron 5 & $\mathrm{G}>\mathrm{A}$ & 0.15 & 0.16 & 0.830 & 1.000 \\
\hline 9 & rs 17200319 & 37126240 & Intron 7 & $\mathrm{~A}>\mathrm{G}$ & 0.06 & 0.06 & 0.901 & 1.000 \\
\hline 16 & rs1924303 & 37145506 & Intron 5 & $\mathrm{C}>\mathrm{T}$ & 0.16 & 0.16 & 0.909 & 1.000 \\
\hline 31 & rs7331005 & 37258896 & Intron 1 & $\mathrm{~A}>\mathrm{T}$ & 0.44 & 0.44 & 0.952 & 1.000 \\
\hline 21 & rs17201866 & 37162409 & Intron 4 & $\mathrm{~A}>\mathrm{T}$ & 0.11 & 0.11 & 0.992 & 1.000 \\
\hline 25 & rs17203407 & 37213086 & Intron 3 & $\mathrm{C}>\mathrm{T}$ & 0.10 & 0.10 & 0.996 & 1.000 \\
\hline 4 & rs17199750 & 37112357 & Intron 8 & $\mathrm{G}>\mathrm{A}$ & 0.10 & 0.10 & 0.996 & 1.000 \\
\hline
\end{tabular}

SNPs are displayed in decreasing order of uncorrected $P$-values. The last column gives $P$-values corrected for multiple comparisons using permutation analysis ( 1,000 permutations). There was no significant association with the other phenotypes

and Hirschhorn 2005). Balancing the demonstrated limitations of our study with the gain of using a well-characterized, EEG-based endophenotype for IGE in the largest cohort of probands published so far on the one hand and the problem of false-positive results with the risk of loosing false-negative results when applying conservative correction methods on the other hand, we conclude that our results suggest a potential role of TRPC4 in photosensitive IGE and justify further studies investigating the contribution of TRPC4 to photosensitivity, increased cerebral excitability and epileptogenesis.

We selected TRPC4 as a candidate gene for photosensitivity by its function and possible role in epileptogenesis and expression in the central nervous system. Comprising $41 \%$ of all TRPC channel expression, TRPC 4 is the subtype with highest expression in the brain (Riccio et al. 2002; Fowler et al. 2007). The protein coded by TRPC4 is a transient receptor potential cation channel permeable for 
Table 3 Haplotypes within blocks of LD
$P$-Values $<0.05$ (uncorrected) are marked in bold letters, polymorphisms from Table 1 in blue. $P$-Values do not survive correction for multiple comparisons

\begin{tabular}{|c|c|c|c|c|}
\hline Haplotype & Frequency & $\begin{array}{l}\text { Frequency } \\
\text { cases }\end{array}$ & $\begin{array}{l}\text { Frequency } \\
\text { controls }\end{array}$ & $P$ Value \\
\hline \multicolumn{5}{|l|}{ Block $1(1-2)$} \\
\hline $\mathrm{AC}$ & 0.344 & 0.319 & 0.348 & 0.403 \\
\hline $\mathrm{CA}$ & 0.342 & 0.312 & 0.347 & 0.311 \\
\hline $\mathrm{CC}$ & 0.324 & 0.370 & 0.305 & 0.059 \\
\hline \multicolumn{5}{|l|}{ Block 2 (3-15) } \\
\hline ACACAAAAACCCA & 0.358 & 0.341 & 0.364 & 0.514 \\
\hline ACAACCAAAACCC & 0.260 & 0.228 & 0.268 & 0.219 \\
\hline CCCACAACCAACA & 0.116 & 0.169 & 0.107 & 0.010 \\
\hline CCCACAACCACCA & 0.085 & 0.087 & 0.085 & 0.935 \\
\hline AAAACACACACAA & 0.055 & 0.052 & 0.056 & 0.812 \\
\hline AAAACAAACACAA & 0.047 & 0.047 & 0.048 & 0.993 \\
\hline ACAACAAACACAA & 0.047 & 0.043 & 0.048 & 0.790 \\
\hline \multicolumn{5}{|l|}{ Block 3 (17-22) } \\
\hline ACCAAA & 0.340 & 0.325 & 0.342 & 0.635 \\
\hline CCAAAA & 0.277 & 0.246 & 0.283 & 0.263 \\
\hline CAAAAA & 0.156 & 0.174 & 0.153 & 0.427 \\
\hline ACACCA & 0.114 & 0.115 & 0.114 & 0.967 \\
\hline CAAAAC & 0.064 & 0.099 & 0.058 & 0.023 \\
\hline ACACAA & 0.046 & 0.040 & 0.047 & 0.662 \\
\hline \multicolumn{5}{|l|}{ Bock 4 (23-24) } \\
\hline AA & 0.487 & 0.458 & 0.493 & 0.348 \\
\hline $\mathrm{CC}$ & 0.382 & 0.355 & 0.387 & 0.380 \\
\hline $\mathrm{CA}$ & 0.131 & 0.188 & 0.121 & 0.008 \\
\hline \multicolumn{5}{|l|}{ Block 5 (25-26) } \\
\hline $\mathrm{AC}$ & 0.541 & 0.576 & 0.534 & 0.263 \\
\hline AA & 0.364 & 0.328 & 0.370 & 0.240 \\
\hline $\mathrm{CC}$ & 0.131 & 0.096 & 0.095 & 0.979 \\
\hline \multicolumn{5}{|l|}{ Block 6 (28-31) } \\
\hline CACA & 0.404 & 0.394 & 0.406 & 0.743 \\
\hline $\mathrm{CCCC}$ & 0.297 & 0.313 & 0.294 & 0.581 \\
\hline CCAC & 0.147 & 0.129 & 0.150 & 0.409 \\
\hline ACCA & 0.100 & 0.094 & 0.101 & 0.731 \\
\hline $\mathrm{CCCA}$ & 0.051 & 0.071 & 0.048 & 0.168 \\
\hline \multicolumn{5}{|l|}{ Block 7 (33-35) } \\
\hline $\mathrm{CCC}$ & 0.482 & 0.523 & 0.474 & 0.195 \\
\hline CAA & 0.289 & 0.273 & 0.292 & 0.570 \\
\hline $\mathrm{ACC}$ & 0.180 & 0.170 & 0.181 & 0.683 \\
\hline $\mathrm{CAC}$ & 0.044 & 0.035 & 0.046 & 0.451 \\
\hline
\end{tabular}

$\mathrm{Ca}^{2+}$-ions which comprises six transmembrane segments and intracellularly located $\mathrm{N}$ - and $\mathrm{C}$-termini. The concept of epilepsy being a channelopathy is widely accepted (Reid et al. 2009). Effects of TRPC4 in the regulation of calcium homeostasis in astrocytes (Song et al. 2005) have been shown. Knockout mice show reduced neurotransmitter release from thalamic dendrites among other implications such as a reduction of the vasorelaxation of arteries and vascular permeability in the lung (Cavalie 2007). Furthermore, TRPC4 is involved in the control of GABA release from dendrites (Munsch et al. 2003) and TRPC4 and TRPC5 seem to be involved in the generation of prolonged epileptiform discharges in hippocampal slices induced by group I metabotropic glutamate receptor agonists (Wang et al. 2007). Various members of the TRPC family, including XTRPC1, a Xenopus homolog of mammalian TRPC1 that forms heteromultimeric protein complexes with TRPC4 and TRPC5, are important for regulatory mechanisms of axon guidance and formation of nerve growth cones and dendritic spines by chemotropic factors 


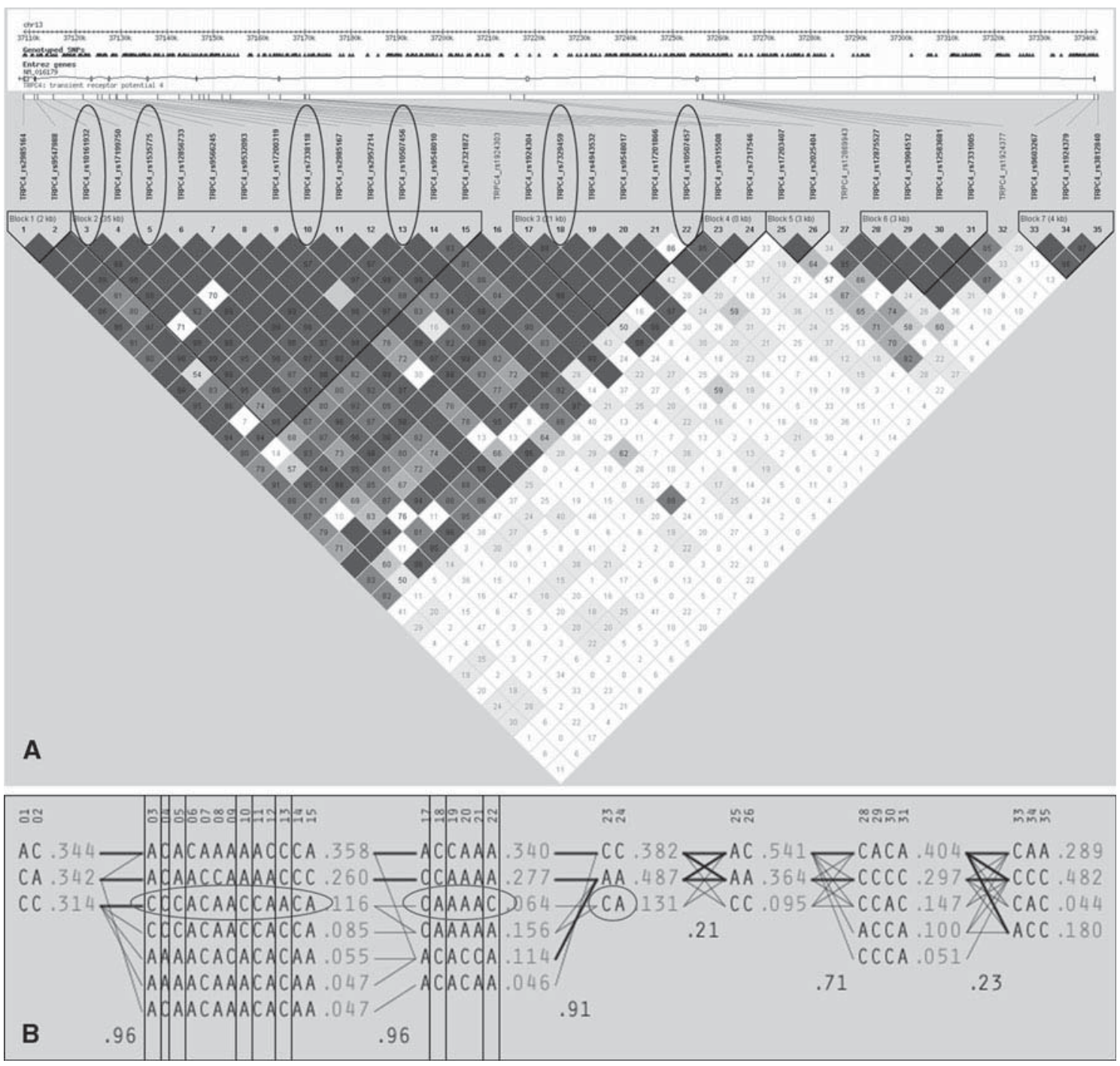

Fig. 1 a Haplotypes within blocks of LD. Polymorphisms with $P$ values $<0.05$ (uncorrected) are marked in blue. $D^{\prime}$ values are displayed and a halftone scheme ranging from white $\left(D^{\prime}<1\right)$ to black $\left(D^{\prime}=1\right)$ is applied. b Each haplotype in a block is shown with its population frequency (in light gray) and connections from one block to the next (thin lines: $>1 \%$, thick lines $>10 \%$ ). In the crossing areas,

such as BDNF and netrin-1 in brain and spinal cord ( $\mathrm{Li}$ et al. 2005; Wang and Poo 2005). Dendritic spines are the main location of excitatory synapses in the brain. This demonstrates various mechanisms by which TRPC4 could contribute to an increased excitability in the brain clinically expressed as photosensitivity.

Cortical control mechanisms of contrast sensitivity seem to be impaired in photosensitive IGE patients (Porciatti et al. 2000), and photosensitivity is thought to be a cortical phenomenon (Siniatchkin et al. 2007). However, subcortical structures might also be involved in photosensitivity: TRPC4 was suggested to contribute to state-dependent processing of visual information and especially visual a value of multiallelic $D^{\prime}$ is shown which represents the level of recombination between the two blocks. Again, polymorphisms with $P$-values $<0.05$ (uncorrected) are marked in black, haplotypes with $P$ values $<0.05$ (uncorrected) in dark gray. (Figures adapted from Haploview $^{\circledR}$ (Barrett et al. 2005))

contrast sensitivity by GABAergic mechanisms in the dorsal lateral geniculate nucleus (Pape et al. 2004). In clinical experience, the occurrence and severity of PPR during intermittent photic stimulation seems to be dependent on the time of the day. JME as an epilepsy syndrome with particularly high incidence of PPR is frequently associated with generalized tonic-clonic seizures occurring especially in the morning, on awaking (Badawy et al. 2009). Both examples demonstrate some extent of state dependency of epileptic symptoms.

In summary, we found suggestive associations of SNP variants in TRPC4, a transient receptor potential cation channel, with the combined phenotype of photosensitivity 
and idiopathic generalized epilepsy but not with the broad PPR phenotype. This indicates a possible role of TRPC4 in the pathophysiology of PPR and IGE as well as genetic heterogeneity within the PPR endophenotype. Further studies including larger numbers of photosensitive probands and controls are needed to clarify the relevance of TRPC4 for PPR and IGE.

Acknowledgments We thank all individuals and their families for participating in this study. It was supported by grants from the European Community (FP6 Integrated Project EPICURE, LSMH-CT2006-037315; FP6 MEXCT visual sensitivity \# 024224, DK-NT); the German Research Foundation (SA434/4-2, TS); the German Federal Ministry of Education and Research (National Genome Research Network, NGFNplus: EMINet, grant no. 01GS08120, TS); The Netherlands National Epilepsy Fund (NEF, grant no. 04-08 to BPCK, DL); The Netherlands Organization for Scientific Research (NOW, grant no. 917.66.315, BPCK and CGFdK); the Christian-AlbrechtsUniversity Kiel, Germany (SvS) and the German Epilepsy Society (DGfE, Otfrid-Foerster-Stipendium, SvS).

Disclosure of conflicts of interest: None of the authors has any conflict of interest to disclose.

\section{References}

Appleton, R., Beirne, M., \& Acomb, B. (2000). Photosensitivity in juvenile myoclonic epilepsy. Seizure, 9, 108-111.

Badawy, R. A., Macdonell, R. A., Jackson, G. D., \& Berkovic, S. F. (2009). Why do seizures in generalized epilepsy often occur in the morning? Neurology, 73, 218-222.

Barrett, J. C., Fry, B., Maller, J., \& Daly, M. J. (2005). Haploview: Analysis and visualization of LD and haplotype maps. Bioinformatics, 21, 263-265.

Cannon, T. D., \& Keller, M. C. (2006). Endophenotypes in the genetic analyses of mental disorders. Annual Review of Clinical Psychology, 2, 267-290.

Cavalie, A. (2007). Ionic channels formed by TRPC4. Handbook of Experimental Pharmacology, 179, 93-108.

Covanis, A. (2005). Photosensitivity in idiopathic generalized epilepsies. Epilepsia, 46(Suppl 9), 67-72.

Darbar, D., Hardy, A., Haines, J. L., \& Roden, D. M. (2008). Prolonged signal-averaged P-wave duration as an intermediate phenotype for familial atrial fibrillation. Journal of the American College of Cardiology, 51, 1083-1089.

Dibbens, L. M., Ekberg, J., Taylor, I., Hodgson, B. L., Conroy, S. J., Lensink, I. L., et al. (2007). NEDD4-2 as a potential candidate susceptibility gene for epileptic photosensitivity. Genes Brain Behaviour, 6, 750-755.

Doose, H., Gerken, H., Volzke, E., \& Volz, C. (1969). Investigations on the genetics of photosensitivity. Electroencephalography and Clinical Neurophysiology, 27, 625.

Engel, J., Jr. (2001). A proposed diagnostic scheme for people with epileptic seizures and with epilepsy: Report of the ILAE Task Force on Classification and Terminology. Epilepsia, 42, 796-803.

Fisher, R. S., Harding, G., Erba, G., Barkley, G. L., \& Wilkins, A. (2005). Photic- and pattern-induced seizures: A review for the Epilepsy Foundation of America Working Group. Epilepsia, 46, 1426-1441.

Fowler, M. A., Sidiropoulou, K., Ozkan, E. D., Phillips, C. W., \& Cooper, D. C. (2007). Corticolimbic expression of TRPC4 and TRPC5 channels in the rodent brain. PLOS ONE, 2, e573.
Freichel, M., Vennekens, R., Olausson, J., Stolz, S., Philipp, S. E., Weissgerber, P., et al. (2005). Functional role of TRPC proteins in native systems: Implications from knockout and knock-down studies. Journal of Physiology, 567, 59-66.

Gottesman, I. I., \& Gould, T. D. (2003). The endophenotype concept in psychiatry: Etymology and strategic intentions. American Journal of Psychiatry, 160, 636-645.

Helbig, I., Scheffer, I. E., Mulley, J. C., \& Berkovic, S. F. (2008). Navigating the channels and beyond: Unravelling the genetics of the epilepsies. Lancet Neurology, 7, 231-245.

ILAE. (1989). Proposal for revised classification of epilepsies and epileptic syndromes. Commission on classification and terminology of the international league against epilepsy. Epilepsia, 30, 389-399.

Lalouel, J. M., Le Mignon, L., Simon, M., Fauchet, R., Bourel, M., Rao, D. C., et al. (1985). Genetic analysis of idiopathic hemochromatosis using both qualitative (disease status) and quantitative (serum iron) information. American Journal of Human Genetics, 37, 700-718.

Li, Y., Jia, Y. C., Cui, K., Li, N., Zheng, Z. Y., Wang, Y. Z., et al. (2005). Essential role of TRPC channels in the guidance of nerve growth cones by brain-derived neurotrophic factor. Nature, 434, 894-898.

Lorenz, S., Taylor, K. P., Gehrmann, A., Becker, T., Muhle, H., Gresch, M., et al. (2006). Association of BRD2 polymorphisms with photoparoxysmal response. Neuroscience Letters, 400, 135-139.

McKay, R. R., Szymeczek-Seay, C. L., Lievremont, J. P., Bird, G. S., Zitt, C., Jungling, E., et al. (2000). Cloning and expression of the human transient receptor potential 4 (TRP4) gene: Localization and functional expression of human TRP4 and TRP3. Biochemical Journal, 351(Pt 3), 735-746.

Mullen, S. A., Crompton, D. E., Carney, P. W., Helbig, I., \& Berkovic, S. F. (2009). A neurologist's guide to genome-wide association studies. Neurology, 72, 558-565.

Munsch, T., Freichel, M., Flockerzi, V., \& Pape, H. C. (2003). Contribution of transient receptor potential channels to the control of GABA release from dendrites. Proceedings of the National Academy of Sciences of the United States of America, 100, 16065-16070.

Newton-Cheh, C., \& Hirschhorn, J. N. (2005). Genetic association studies of complex traits: Design and analysis issues. Mutation Research, 573, 54-69.

Pape, H. C., Munsch, T., \& Budde, T. (2004). Novel vistas of calcium-mediated signalling in the thalamus. Pflügers Archiv, 448, 131-138.

Porciatti, V., Bonanni, P., Fiorentini, A., \& Guerrini, R. (2000). Lack of cortical contrast gain control in human photosensitive epilepsy. Nature Neuroscience, 3, 259-263.

Reid, C. A., Berkovic, S. F., \& Petrou, S. (2009). Mechanisms of human inherited epilepsies. Progress in Neurobiology, 87, 41-57.

Riccio, A., Medhurst, A. D., Mattei, C., Kelsell, R. E., Calver, A. R., Randall, A. D., et al. (2002). mRNA distribution analysis of human TRPC family in CNS and peripheral tissues. Brain Research. Molecular Brain Research, 109, 95-104.

Siniatchkin, M., Groppa, S., Jerosch, B., Muhle, H., Kurth, C., Shepherd, A. J., et al. (2007). Spreading photoparoxysmal EEG response is associated with an abnormal cortical excitability pattern. Brain, 130, 78-87.

Skol, A. D., Scott, L. J., Abecasis, G. R., \& Boehnke, M. (2006). Joint analysis is more efficient than replication-based analysis for twostage genome-wide association studies. Nature Genetics, 38, 209-213.

Song, X., Zhao, Y., Narcisse, L., Duffy, H., Kress, Y., Lee, S., et al. (2005). Canonical transient receptor potential channel 4 (TRPC4) co-localizes with the scaffolding protein ZO-1 in human fetal astrocytes in culture. Glia, 49, 418-429. 
Stefansson, H., Rye, D. B., Hicks, A., Petursson, H., Ingason, A., Thorgeirsson, T. E., et al. (2007). A genetic risk factor for periodic limb movements in sleep. New England Journal of Medicine, 357, 639-647.

Stephani, U., Tauer, U., Koeleman, B., Pinto, D., Neubauer, B. A., \& Lindhout, D. (2004). Genetics of photosensitivity (photoparoxysmal response): A review. Epilepsia, 45(Suppl 1), 19-23.

Tobler, A. R., Short, S., Andersen, M. R., Paner, T. M., Briggs, J. C., Lambert, S. M., et al. (2005). The SNPlex genotyping system: A flexible and scalable platform for SNP genotyping. Journal of Biomolecular Techniques, 16, 398-406.

Waltz, S., Christen, H. J., \& Doose, H. (1992). The different patterns of the photoparoxysmal response-a genetic study. Electroencephalography and Clinical Neurophysiology, 83, 138-145.
Wang, M., Bianchi, R., Chuang, S. C., Zhao, W., \& Wong, R. K. (2007). Group I metabotropic glutamate receptor-dependent TRPC channel trafficking in hippocampal neurons. Journal of Neurochemistry, 101, 411-421.

Wang, G. X., \& Poo, M. M. (2005). Requirement of TRPC channels in netrin-1-induced chemotropic turning of nerve growth cones. Nature, 434, 898-904.

Wu, X., Babnigg, G., Zagranichnaya, T., \& Villereal, M. L. (2002). The role of endogenous human Trp4 in regulating carbacholinduced calcium oscillations in HEK-293 cells. The Journal of Biological Chemistry, 277, 13597-13608. 